\title{
Predicting Alzheimer's Disease Onset
}

\author{
Harold I. Zeliger
}

\begin{abstract}
Recently, a method for assigning the probability of disease onset to all people, those clinically ill as well as those without prevalent disease has been described and termed the Oxidative Stress Index (OSI). The OSI, as originally formatted, does not predict which disease will more likely develop, only that further disease is predicted with increased OSI. It is hypothesized here that the OSI may be used to demonstrate which parameters are more contributory to the onset of a particular disease if it is measured at the time of onset of that disease. To test this hypothesis, the OSI has been reformatted to serve in that capacity for Alzheimer's disease (AD) with the anticipation that the OSI could serve to predict not only the likelihood of onset, but also identify those parameters that are most contributory to AD.
\end{abstract}

Index Terms - Alzheimer's Disease; Oxidative Stress; Oxidative Stress Index; Predicting Disease Onset.

\section{INTRODUCTION}

People with chronic diseases and those who are disease free but living unhealthy lifestyles are known to be candidates for numerous non-communicative diseases, as well as more frequent and more severe bouts with infectious diseases.

Recently, a method for assigning the probability of disease onset to all people, those clinically ill as well as those without prevalent disease has been described and termed the Oxidative Stress Index (OSI). This method is a non-invasive diagnostic protocol based upon a questionnaire addressing oxidative stress (OS) elevating factors that include disease status, lifestyle and environmental exposure with the sum of the positive answers equal to the OSI [Zeliger, 2017].

The OSI, as originally formatted, does not predict which disease will more likely develop, only that further disease is predicted with increased OSI. It is hypothesized here that the OSI may be used to demonstrate which parameters are more contributory to the onset of a particular disease if it is measured at the time of onset of that disease. To test this hypothesis, the OSI has been reformatted to serve in that capacity for Alzheimer's disease (AD) with the anticipation that the OSI could serve to predict not only the likelihood of onset, but also identify those parameters that are most contributory to $\mathrm{AD}$.

\section{METHODS}

The hypothesis proposed here is based upon a literature review of published studies on the causes of OS, parameters associated with the onset of $\mathrm{AD}$, OS induced disease,

Published on May 17, 2019.

Herald I. Zeliger, Zeliger Research and Consulting, 41 Wildwood Drive, Cape Elizabeth, Maine 04107, USA. (email:hiz@zeliger.com) methods of measuring OS and the empirical and mechanistic associations between $\mathrm{AD}$ and $\mathrm{OS}$.

\section{RESUlTS}

\section{A. Oxidative Stress}

It is well known that all disease is accompanied by elevated OS, a property whose status can be measures by a number of biomarkers, including F2-Isoprostanes, lipid hydroxides and hydroperoxides, hydroxycholesterols, aldehydes and ketones [Zeliger, 2016]. Of these, the most widely used is malondialdehyde (MDA), which is stable in serum, as well as readily and accurately analyzed for [Nielsen, et al, 1997]. MDA level, however, can vary widely depending upon food eaten, environmental exposures, state of one's health or even the time of day when serum is drawn [Nielsen, et al, 1997]. The OSI questionnaire reduces such uncertainty by addressing nineteen different aspects of a person's regular life, including disease status, medications, diet, employment, environmental exposures, and stress, etc., that elevate OS.

Oxidative stress has been shown to be a crucial mechanistic component of $\mathrm{AD}$ onset [Liu, et al., 2015; Huang, et al., 2015; Kamat, et al., 2016; Tonnies and Trushina, 2017] and has been definitively associated with brain neuroinflammation and blood-brain barrier dysfunction that is both a cause and consequence of $\mathrm{AD}$ generating hyperpermeability that leads to the absorption of as well as generation of OS inducing species in the brain [Zhang \& Jiang, 2015; Erickson \& Banks, 2013; Najjar, et al., 2013].

It is also known that disease onset likelihood is related to total oxidative stress arising from numerous sources [Zeliger 2016 and the references contained therein]. These are listed in Appendix (Table I).

\section{B. Dose Response Relationship}

Total Oxidative Stress has been shown to be related to disease onset, whether coming from single sources or from a combination of other sources in a dose response relationship (DRR) [Zeliger, 2016]. A single source example of this effect as it applies to AD is exposure to radon [Lehrer, et al., 2017]. Multiple source examples are lifetime cigarette smoking [Mons, et al., 2013; Durazzo, et al., 2014] and simultaneous exposure to heavy metals and polynuclear aromatic hydrocarbons [Deng, et al., 2019]. DRRs for increased OS include exposures to trichloroethylene, perchloroethylene, air pollution, tobacco smoking, metals (including arsenic, cadmium and mercury), polynuclear aromatic hydrocarbons [Kuang, et al., 2013; Zeliger, 2016] and ultra violet radiation [Agarwal, et al, 1987]. 


\section{Parameters Known to Increase Likelihood of $A D$ Onset}

$\mathrm{AD}$ is characterized by deposition of amyloid-beta plaques, hyperphosphorylated tau protein and neurofibrillary tangles [Kamat et al., 2016]. It is well known that elevated oxidative stress is associated with increased likelihood of AD onset [Christen, 2000; Perry, et al., 2002; Huang, et al., 2016, Durazzo, et al., 2014, Durazzo, et al., 2014a ]. The individual parameters and their references are listed in Appendix (Table II). Oxidative stress has also been shown to be a crucial mechanistic component of AD onset [Liu, et al., 2015; Huang, et al., 2015; Kamat, et al., 2016; Tonnies and Trushina, 2017.

Several parameters have been shown to increase the likelihood of AD onset. These and representative references for them are shown in Appendix (Table II).

\section{Aging}

Aging is not a disease. Rather, it is a natural consequence of living, but is accelerated by OS. It is widely theorized that excessive OS contained within

mitochondria damage the mitochondria which in turn leads to increases in OS. Once started, this cycle leads to further increased OS and aging, making OS both the cause the result of disruption of homeostasis which leads to aging and onset of Alzheimer's disease as well as type 2 diabetes, cardiovascular diseases and COPD [Dato, et al., 2013; Cencioni, at al., 2013; Guillaumet-Adkins, et al., 2017]. As we age, free radicals are excessively generated and overwhelm the body's natural antioxidant response, leading to increased OS [Dato, et al., 2013]. Actions that can be taken to slow down the aging process are discussed in the prevention section below.

\section{E. Genetics and Epigenetics}

Genetics and epigenetics have been shown to contribute to the onset of AD. It is well known that AD runs in families and that inheriting one copy of the APOE4 gene triples the risk of developing $\mathrm{AD}$, while inheriting 2 copies of APOE4 increases the risk by 10 to 15 times [Jiang, et al., 2013; Dato, et al., 2013; Guillaumet-Adkins, et al., 2017; Cencioni, et al., 2013].

Epigenetic changes are heritable changes in gene expression that are not the result of alterations in the DNA sequence. These changes do, however, elevate OS and have been linked to the onset of cardiovascular diseases, respiratory system diseases and neurological system diseases, including AD [Cencioni, et al., 2013; Jiang, et al., 2013; Guillaumet-Adkins, et al., 2017]. The presence of AD in blood relatives has been shown to be associated with greater incidence of the disease, The likelihood of an individual falling ill with $\mathrm{AD}$ increases with increasing $\mathrm{AD}$ prevalence in parents, grandparents and siblings [National Institute of Aging, 2015].

\section{F. Co-Morbidities}

$\mathrm{AD}$ is co-morbid with numerous other diseases. These include hypertension, cardiovascular diseases, type 2 diabetes, ocular disorders, sleep disorders, cognitive and behavioral deficits, bladder and bowel control problems, obesity and musculoskeletal diseases [Barbagallo \& Dominguez, 2014; Bannon, 2002; Duthie, et al., 2011;
Bunn, et al., 2014; Bauer, et al., 2014; Poblador-Plou, et al., 2014; Fafara, et al., 2014; Zeliger, 2014; Alford et al., 2018; Naderali, et al., 2009; Karki, et al., 2017]

Though mechanistic explanations have been offered for some of the co-morbid pairs, $\mathrm{AD}$ and $\mathrm{T} 2 \mathrm{D}$ or obesity, for example [Profenno, et al., 2009; Barbargallo \& Dominguez, 2014; Karki, et al., 2017], other AD co-morbidities are yet to be mechanistically tied together. However, all of the diseases that are co-morbid with $\mathrm{AD}$ are, like $\mathrm{AD}$, known to be caused be elevated OS [Zeliger, 2016].

\section{G. Late Onset of $A D$}

OS caused diseases manifest themselves only after long term (years) exposure to causative agents. Examples of such diseases are cardiovascular diseases, type 2 diabetes, COPD, cancers and $\mathrm{AD}$. In the case of $\mathrm{AD}$, even early onset of disease, before age 65 , follows many years of exposure to OS causing stimuli and in the case of persistent organic pollutants, storage in the body's adipose tissue for up to decades[Cencioni, et al., 2013; Zeliger 2013; Zeliger \& Lipinski 2015].

\section{H. Prevention}

Further evidence for the relationship of $\mathrm{AD}$ with $\mathrm{OS}$ comes from a consideration of lifestyle changes known to lower AD incidence. It is estimated that as many as one half of the cases of $\mathrm{AD}$ are attributable to the following eight modifiable factors [Barnes and Yaffe, 2011]. These include:

Acting to prevent and manage type 2 diabetes

- Acting to prevent or treat hypertension

- Not smoking

- Maintaining physical activity

- Maintaining cognitive activity

- Treating depression, if present

- Prevent or reverse obesity

- Maintaining a diet that is low caloric, high in fruits and vegetables, whole grains, and nutritional antioxidants with reduced quantities of carbohydrates, saturated fats, red and processed meats. There are several versions of such a diet. The Mediterranean diet includes the consumption of large quantities of extra virgin olive oil and moderate quantities of red wine [Dato, et al., 2013]. Other examples include the Okinawan diet, (followed by residents of Okinawa, Japan), the Dash diet (developed to stop hypertension) and the Portfolio diet (aimed at reducing cholesterol levels ) [Wilcox, et al., 2014].

It has also been reported that $\mathrm{AD}$ prevalence can be significantly reduced by properly treating the following conditions, which undermine immune system vitality and lead to chronic inflammation, which is known to elevate OS [Trempe \& Lewis, 2018, Zeliger, 2017].

- Chronic migraines

- mood disorders

- Eye diseases

- Metabolic syndromes

- chronic viral diseases

- hormonal diseases

- autoimmune diseases

All of the AD causative factors discussed above raise OS, 
while the preventative factors all lower OS. It is, therefore, reasonably hypothesized that avoiding other OS elevating factors such as chronic infections which stresses the immune system and result in chronic inflammation, as well as chronic environmental exposures to toxic chemicals and radiation, which also elevated $\mathrm{OS}$ can delay onset of AD by years. And that is what the OSI does.

\section{Questionnaires}

Questionnaires, such as the Charlson Comorbidity Index, are routinely used to solicit patient background information on prevalent diseases, symptoms and likelihood of further disease onset [Charlson et al., 1987]. The Alzheimer's Questionnaire is another example [Sabbagh, et al., 2010].

\section{DISCUSSION}

As all of the AD causative factors raise OS, and all the preventative $\mathrm{AD}$ factors lower $\mathrm{OS}$, it is, therefore, reasonably hypothesized that avoiding other OS elevating factors such as chronic infections which stresses the immune system and result in chronic inflammation, as well as chronic environmental exposures to toxic chemicals and radiation, which also elevate $\mathrm{OS}$, can delay onset of $\mathrm{AD}$ by years.

From the results described above, it is clear that there is no single cause of $\mathrm{AD}$, but that $\mathrm{AD}$ onset can be triggered by numerous parameters, all of which are associated with elevating OS.

It is hypothesized here that increased levels of OS is ultimately responsible for increased incidence of $\mathrm{AD}$, that all parameters which contribute to OS elevation increase the likelihood of $\mathrm{AD}$ onset and that total OS, measured via the OSI questionnaire administered to the patient or surrogate at the time of first diagnosis of AD can shed light on, not only the patient's total OS, but also, via analysis of statistically significant patient results, on those parameters which are primary contributors to AD onset.

Accordingly, all factors known to raise OS have been incorporated into the modified OSI questionnaire shown in Appendix (Table IIII). This version of the OSI contains genetic and epigenetic items known to correlate to increased incidence of AD. These are:

As discussed above, exposures to numerous environmental agents have been associated with increased prevalence of $\mathrm{AD}$. These have also been incorporated into the questionnaire.

\section{A. Strengths}

The OSI is non-invasive, yet predicts OS levels and offers insights into which parameters are the most contributory to $\mathrm{AD}$ onset. Individual items in the OSI are presented in alphabetical order and may differ widely from one item to the next. This is deliberate so that the patient or surrogate addressing the OSI is required to consider each item alone, rather than a part of a series of related questions, which could cause the responder to just check all the items in a single set.

\section{B. Limitations}

All parameters in the OSI carry equal weight. Clearly, some parameters are more detrimental to health to others,
Parkinson's disease versus the chronic sinusitis, for example. That said, more serious diseases will generally produce greater number of symptoms and require more medications than less severe ones. The large number of items in the OSI, also reduce to importance of any one item to the overall score obtained.

\section{CONCLUSIONS}

The hypothesis presented here is that $\mathrm{AD}$ is an oxidative stress induced disease, as all established causes of AD have been shown to raise OS. Accordingly, anything that raises OS is potentially a contributing cause to AD. Conversely, anything that lowers OS, or prevents raising it, potentially delays or prevents $\mathrm{AD}$ onset. It is anticipated that statistical analysis of data collected will shed light on those parameters that most contributory to the onset of AD.

The Oxidative Stress Index measured at time of AD onset is potentially a valuable tool that can lead to an understanding of what the primary causative agents of $\mathrm{AD}$ are.

\section{APPENDIX}

TABLE I: SOURCES KNOWN TO INCREASE OXIDATIVE STRESS [ZELIGER 2016].

\begin{tabular}{l}
\hline \hline Parameter \\
\hline Toxic Chemical Exposures \\
Radiation Exposure \\
Tobacco Smoke \\
Alcohol \& Recreational Drugs \\
Pharmaceutical Drugs \\
Brain trauma \\
Inflammation \\
Heat and Cold Exposures \\
Diet \\
Sleep Deprivation \\
Communicative Diseases Present \\
Non-communicative (environmental) Diseases \\
Chronic psychological Stress \\
Aging \\
Lifestyle Choices
\end{tabular}

TABLE II: PARAMETERS SHOWN TO INCREASE THE LIKELIHOOD OF AD ONSET AND REPRESENTATIVE REFERENCES FOR EACH

\begin{tabular}{ll}
\hline \hline Parameter & References \\
\hline Air pollution & $\begin{array}{l}\text { Block \& Calderon-Garciduenas, 2009; } \\
\text { Moulton \& Yang, 2012; Carey, et al., 2018; } \\
\text { Kilian \& Kitazawa, 2018 }\end{array}$ \\
\hline Pesticides & Yan, et al., 2016 \\
\hline Heavy metals & Adlard \& Bush, 2018; Lee, et al., 2018 \\
\hline Radiation & Tang, 2018; Lehrer, et al., 2017 \\
\hline Smoking & Ott, et al., 1998; Durazzo, et al., 2014a \\
\hline Brain injury & $\begin{array}{l}\text { Turner, et al., 2016; Yuan \& Wang, 2018, } \\
\text { Breunig, et al., 2013 }\end{array}$ \\
\hline Chronic inflammation & $\begin{array}{l}\text { Dunn, et al., 2005; Misiak, et al., 2012; } \\
\text { Trempe \& Lewis, 2018 }\end{array}$ \\
\hline $\begin{array}{l}\text { Infectious diseases - viral, } \\
\text { fungal, bacterial and } \\
\text { parasitic }\end{array}$ & $\begin{array}{l}\text { Honjo, et al., 2009; D'Aiuto, et al., 2010; } \\
\text { Karim, et al., 2014; Sochocka, et al., 2017; } \\
\text { Eimer, et al., 2018; Readhead, et al., 2018 }\end{array}$ \\
\hline Diet & Luchsinger, et al., 2002 \\
\hline Traumatic brain injury & $\begin{array}{l}\text { Yanjun, et al., 2017; Ramos-Cejudo, et al., } \\
\text { 2018 }\end{array}$ \\
\hline $\begin{array}{l}\text { Chronic Psychological } \\
\text { stress }\end{array}$ & Machado, et al., 2014; Justice 2018 \\
\hline Obesity & $\begin{array}{l}\text { Profenno, et al., 2010, Naderali et al., 2011; } \\
\text { Alford, et al., 2018 }\end{array}$ \\
\hline $\begin{array}{l}\text { Blood brain barrier } \\
\text { breakdown }\end{array}$ & Lockhead, et al., 2010; Nation, et al., 2019 \\
\hline Aging & $\begin{array}{l}\text { Dato, et al., 2013; Cencioni, at al., 2013, } \\
\text { Guillaumet-Adkins, et al., 2017 }\end{array}$ \\
\hline \hline
\end{tabular}




\begin{tabular}{ll}
\hline \hline Genetics and epigenetics & $\begin{array}{l}\text { Jiang, et al., 2013; Dato, et al., 2013; } \\
\text { Guillaumet }\end{array}$ \\
\hline family history & $\begin{array}{l}\text { Adkins, et al., 2017; Cencioni, et al., 2013; } \\
\text { National Institute of Aging, 2015 }\end{array}$ \\
\hline \multirow{2}{*}{ AD co-morbidities } & $\begin{array}{l}\text { Bannon, 2011; Duthie, et al., 2011; Bunn, et } \\
\text { al, 2014; Bauer, et al., 2014; Poblador-Plou, } \\
\text { et al. }\end{array}$ \\
\hline \hline
\end{tabular}

TABLE III: OXIDATIVE STRESS INDEX

\begin{tabular}{l}
\hline \multicolumn{2}{c}{ OXIDATIVE STRESS INDEX (OSI) CHECK LIST } \\
\hline GENDER $\quad$ Female \\
\hline AGE OF ONSET \\
\hline FAMILY HISTORY \\
\hline$\quad$ Mother with Alzheimer's disease \\
Father with Alzheimer's disease \\
Siblings with Alzheimer's disease (put one check for each sister \\
or brother) \\
Grandmother with Alzheimer's disease (put one check for each \\
grandmother) \\
$\begin{array}{l}\text { Grandfather with Alzheimer's disease (put one check for each } \\
\text { grandfather) }\end{array}$ \\
Total Family History Checks
\end{tabular}

Total Family History Checks

AGE

Check all age boxes that apply. If, for example, you are 55 years old check the first two boxes. If you're 82 , check all 5 of these boxes

40 or older

50 or older

60 or older

70 or older

80 or older

Find your healthy weight, on the weight chart (see table 2.2 on page 46). Check all the weight boxes that apply. If, for example you are 40 pounds over your recommended weight check the first three boxes and add three checks to the total.

Find your recommended weight on the weight chart at the end of the OSI checklist.

10 - 20 pounds overweight

$21-40$ pounds overweight

31 - 60 pounds overweight

61 - 80 pounds overweight

81 or more pounds overweight

Total age and weight checks

\section{ILLNESSES and CONDITIONS}

Check all illnesses or conditions that you have been diagnosed with and currently have.

Acne

ADHD (Attention Deficit Hyperactivity Disorder)

AIDS or HIV

Alcohol addiction

Allergic rhinitis (sinus inflammation)

ALS (Lou Gehrig's disease)

Anemia

Anorexia

Anxiety disorder

Appetite loss

Arthritis

Asthma

Autism and ASD

Autism or autism spectrum disorder (ASD)

Benign prostate hyperplasia (enlargement - BPH)

Bipolar disorder

Bronchitis (chronic)

Bulimia

Bulging or herniated disc

Carpal tunnel syndrome

Cancer - Check all that apply. If stage three, for example, check first three

Cancer - stage 1

Cancer - stage 1 or 2

Cancer - stage 1,2 or 3

Cancer - stage 1,2,3 or 4

Cardiovascular disease

Chronic Fatigue Syndrome (CFS)

Crohn's disease

Common cold (frequent)

COPD (chronic obstructive pulmonary disease)

Crohn's disease
Dementia

Dengue fever

Dental abscess (frequent)

Depression

Diabetes (type 1 or type 2)

Diarrhea (frequent)

Diverticulitis

Drug addiction

Eczema

Emphysema

Endometriosis

Epilepsy

Fibromyalgia (FM)

Flu

Frequent common colds

Frequent headaches

Frequent indigestion

Frequent infection

Frequent itching

Frequent rashes

Frequent sinus infections (sinusitis)

Glaucoma

Gout

Gum disease

Heart attack

Heart Disease or heart problems

Hemorrhoids

Hepatitis B (chronic)

High blood pressure (hypertension)

High cholesterol

Herpes

Inflammatory bowl disease

Irritable bowel syndrome (IBS)

Kidney disease

Leukemia

Liver cirrhosis

Liver disease

Lupus

Lyme disease

Macular degeneration

Malaria

Metabolic syndrome (pre-diabetes)

Middle ear infection (frequent)

Migraine headaches

Multiple chemical sensitivity (MCS)

Multiple sclerosis

Obesity

Osteoarthritis

Osteoporosis

Parkinson's disease

Periodontal disease (swollen or bleeding gums)

Post-traumatic stress disorder (PTSD)

Rocky Mountain spotted fever

Psoriasis

Rosacea

Schizophrenia

Seizures

Sexually transmitted disease (STD)

Shingles

Sjogren's syndrome

Sleep apnea

Stroke

TB (Tuberculosis)

Thyroid disease

Tourette syndrome

Tremors

Ulcers

Varicose veins

West Nile Fever

Yellow fever

Zika

Write in the names of any other illnesses you have that were not listed above and check those.

Total Disease Checks

DISEASE START

How

many of 
the

diseases

checked

above

started in

\section{SYMPTOMS}

The past 2 years?

The past 5 years?

The past 10 years?

Check all the symptoms that you currently experience.

Abdominal pain (frequent)

Allergic reactions to chemicals

Allergic reactions to any foods

Allergic reactions to insects

Allergic reactions to medications

Allergic reactions to plants (Hay fever)

Ankle pain

Attention span decline

Anxiety often

Bleeding gums

Blood in stool

Blood in urine

Blurred or cloudy vision

Bruise easily

Burning when urinating

Butterflies in your stomach often

Change in skin color

Chest pain

Constant chills

Constipation

Cough that is persistent

Coughing or spitting up blood

Decision making difficulties

Decline in learning ability

Decreased eye sight

Decreased sex drive

Diarrhea (frequent)

Difficulty completing familiar tasks

Difficulty concentrating

Difficulty getting warm

Difficulty maintaining balance

Difficulty solving problems

Difficulty swallowing

Difficulty walking

Difficulty concentrating or finding words

Dizziness

Drained of energy

Dreams that are bizarre and recurring

Excessive mucous production

Excessive thirst

Eye discomfort or pain

Eye redness

Fatigue

Feel depressed a lot

Feel less alert or fuzzy headed

Fever

Food allergies

Foot pain

Foot swelling

Fungal infection such as athlete's food that persists

Frequent urination

Graying of hair

Hair loss (not due to chemotherapy)

Have itchy scaly skin rashes

Headaches frequently

Hear voices inside you

Hearing loss that comes on suddenly

Heart palpitations (throbbing)

Heartburn

Hip pain

Hoarseness

Increased susceptibility to infections

Indigestion (frequent)

Insomnia

Irregular periods

Itchy hands

Itchy skin other than hands

Jaw pain

Leg swelling

Learning new things more difficult
Light headedness

Long recovery time from infections

Losing track of time

Loss of coordination

Loss of muscle tone

Loss of taste

Lower back pain

Memory loss

Mood swings from very high to very low and vice versa

Mouth sores that don't go away quickly

Muscle aches that last a long time

Muscle cramps

Muscle spasms

Nasal congestion

Nausea

Neck pain

Nervousness

Nightmares regularly

Nose bleeds

Knee pain

Numbness or tingling in hands or feet

Pain in joints

Heart palpitations

Pelvic pain

Perspire (sweat) profusely

Post nasal drip that lingers

Post traumatic stress disorder (PTSD)

Problems finding the words you want

Rapid hair loss

Rapid heartbeat

Scaly skin

Seizures

Shortness of breath

Shoulder pain that lingers

Sinus pain

Skin mole growth

Skin rashes

Sleep less than 7 hours per night

Sleep more than 9 hours a night

Slow to heal from cuts, bruises or other injuries

Slurred speech

Smaller field of vision

Sore throat that doesn't heal

Stressed out most or all of the time

Stuffy nose

Swollen eye lids

Tics (involuntary movements)

Tingling in the hands or feet

Tire easily

Tired most of the time

Tooth pain

Tremors

Twitching

Unusual vaginal bleeding or discharge

Urination difficulty

Urination pain

Varicose veins

Vomiting

Wake up more than 3 times per night

Weakness

Weight gain

Weight loss (rapid)

Wheezing

Wrinkling or loss of tone in skin

Yawning frequently

Total Symptoms Checks

\section{TEST RESULTS}

The following address results obtained from test doctors ordered done as part of annual examinations. Check all that apply to you.

High or low blood sugar

High or low BUN (blood urea nitrogen)

High or low calcium

High or low carbon dioxide (bicarbonate)

High or low chloride

High cholesterol

High or low creatinine

High glucose

High or low potassium

High PSA 
High or low sodium

High triglycerides

Low blood oxygen

Low potassium

Total Test Results Checks

\section{PRESCRIPTION MEDICINES REGULARLY TAKEN}

Check each of the boxes that apply. If you regularly take five prescription drugs, for example, check all of the first 5 items, so that the total number of items checked equals the total number of prescriptions regularly taken.

1 prescription

2 prescriptions

3 prescriptions

4 prescriptions

5 prescriptions

6 prescriptions

7 prescriptions

8 prescriptions

9 prescriptions

10 or more prescriptions

Have a heart pacemaker

Total Prescription Medicine Checks

DIET

Check each item that applies to the foods that are part of your regular eat.

Alcoholic beverages (beer, wine, spirits) more than 1 drink per day

Artificial sweeteners for coffee or tea

Canned or frozen cooked foods regularly eaten (soups, pastas, meats)

Bread and pasta made primarily from white processed flour

Fast food frequently eaten

Fewer than 3 fruits or vegetables a day

Grilled, smoked or blackened meat, chicken or fish

Food high in fat (whole milk, cheeses, foods cooked with butter and animal fat)

Often eat processed foods (bacon, hot dogs, salami, sausages.

deli meats

Eat red meat more than 2 times a week

Eat foods high in sugar (sweetened drinks and desserts)

Salty food

Total Diet Checks

LIFE STYLE

These items refer to where you live, the type of work you do and chemicals you may be exposed to.

Are a farmer that regularly uses pesticides

Burn wood for heat or for cooking

Constantly use a cell phone

Drink chlorinated water

Drink more than one alcoholic drink per day

Exercise less than one half hour a week

Have mold in your home

Have new (less than 6 months old) carpet in your home

Have pets in your home that you are allergic to

Live down wind from a smoking industrial chimney

Live in a city with air quality alerts

Live or work close to a cell tower

Live or work near high voltage electrical transmission lines

Live near a heavily traveled highway or road

Live near a landfill

Live with a smoke

Regularly experience allergic reactions in your home

Regularly experience allergic reactions in your work place

Regularly use room or furniture deodorants

Regularly play contact sports

Tobacco use. Check all of the items that apply. For example, if you smoke one pack of cigarettes a day, check both of the first 2 items. If you smoke two packs a day, check all of the first 4 items.

Smoke 10 cigarettes or less daily (even just one)

Smoke a pack a day (20 cigarettes)

Smoke a pack and a half a day (30 cigarettes)

Smoke two packs a day (40 cigarettes)

Smoke more than two packs a day

Smoke $1-5$ cigars a day

Smoke 6 or more cigars a day

Use smokeless tobacco

Work as a toll booth collector

Work in very hot or very cold conditions regularly

Work in an adhesives or coatings manufacturing plant
Work in an agricultural chemical manufacturing plant

Work as an automobile, diesel or aircraft mechanic

Work with chemicals on the job regularly

Work in a dusty environment regularly

Work in a landfill

Work in a hair or nail salon

Work in metal refinery or mill

Work as a miner

Work in a noisy environment

Work in a paint, lacquer, stain or varnish manufacturing plan

Work as a painter

Work as a pilot or flight attendant

Work as a pesticide applicator

Work in a petroleum refinery

Work in a plastics manufacturing plant

Work in a plywood or particle board manufacturing plant

Work in a polluted environment (road paver, toll booth

operator, for example)

Work in a water or sewage treatment plant

Work in wood treatment plant

Total Lifestyle Checks

OSI, Total of All Checks

\section{REFERENCES}

Agarwal S, Ghosh A, Chatterjee SN. (1987). Spontaneous release of malondialdehyde from ultra violet lightexposed liposomal membranes. Z Naturforsch 42c:585-588.

Adlard PA, Bush AI. (2018). Metals and Alzheimer's disease: How far have we come in the clinic? J Alzheimer's Dis (2018). 62:1369-1379.

Alford S, Patel D, Perakakis N, Manzoros CS. (2018). Obesity as a risk factor for Alzheimer's disease: weighing the evidence. Obes Rey 19(2):269-280.

Bannon M. (2011). Co-morbidities and Alzheimer's disease: the need for vigilance. QJ Med 104:911-912.

Barbagallo M, Dominguez LJ. (2014). Type 2 diabetes and Alzheimer's disease. World J Diabetes 5(6):889-893.

Barnes DE, Yaffe K. (2011). The projected impact of risk factor reduction on Alzheimer's disease prevalence. Lancet Neurol 10(9):819-828.

Bauer K, Schwartzkopf L, Graessel E, Holle R. (2014). A claims databased comparison of comorbidity in individuals with and without dementia. BMC Geriatrics 14:10. www.biomedcentral.com/14712318/14/10. Accessed January 12, 2019.

Block ML, Caldersom-Garciduenas L. (2009). Air pollution: mechanisms of neuroinflammation \& CNS disease. Tends Nuerosci 32(9):506-516. www.biomedcentral.com/1741-7015/12/192. Accessed January 11, 2019.

Breunig JJ, Guillot-Sestier MV, Town T. (2013). Brain injury, neuroinflammation and Alzheimer's disease. Aging Neuroscience July 2013|Vol 5|Article 5.

Bunn F, Burn AM, Goodman C, Rait G, Norton S, Robinson L, et al. (2014). Comorbidity and dementia: a scoping review of the literature. BMC Med 12:192.

Carey IM, Anderson HR, Atkinson RW, Beevers SD, Cook DG, Strachan DP, et al. (2018). Are noise and air pollution related to the incidence of dementia? A cohort study in London, England. BMJ Open 8(9):e022404. doi: 10.1136/bmjopen-2018-022404. Accessed January $10,2019$.

Cencioni C, Spallotta F, Martelli F, Valente S, Mai A, Zeiher AM, Gaetano C. (2013). Oxidative stress and epigenetic regulation in aging and age-related diseases. Int J Mol Sci 14:17643-17663.

Charlson ME, Pompei P, Ales KL. (1987). A new method of classifying prognostic comorbidity in longitudinal studies: development and validation. J Chronic Dis; 40(5):373-383

Christen Y. (2000). Oxidative stress and Alzheimer's disease. Am J Clin Nutr 71(suppl):621S-629S.

D'Aiuto F, NIbali L, Parkar M, Patel , Suvan J, Donos N. (2010). Oxidative stress, systemic inflammation, and severe periodontitis. J Dent Res 89(11):1241-1246

Dato S, Crocco P, D'Aquila P, de Rango F, Bellizzi D, Rose G, Passarino G. (2013). Exploring the role of genetic variability and lifestyle in oxidative stress response for healthy aging and longevity. Int $\mathrm{J} \mathrm{Mol}$ Sci 14:16443-16472.

Deng Q, DAi X, Feng W, Huang S, Yuan Y, Xiao Y, et al. (2019). Coexposure to metals and polycyclic aromatic hydrocarbons, microRNA expression, and early health damage in coke oven workers. Environ Int 122:369-380. doi: 10.1016/j.envint.2018.11.056. Accessed January 8,2019 . 
Dominy SS, Lynch C, Ermini F. Benedyk M. Marczyk A, Konradi A, et al. (2019). Porphyromonas gingivalis in Alzheimer's disease brains: Evidence for disease causation and treatment with small-molecule inibators. Sci Adv 5:easu3333. Accessed January 31, 2019.

Dunn NDM, Mullee M, Perry VH, Holmes C. (2005). Association between dementia and infectious disease: Evidence from a case-control study. Alzheimer Dis Assoc Disorders 19(2):91-94.

Durazzo TC, Mattsson N, Weiner MW. (2014). Smoking and increased Alzheimer's disease risk: a review of potential mechanisms. Alzheimers Dement (3Suppl):S122-145.

Durazzo TC, Mattsson N, Weiner MW, Korecka M, Trojanowski JQ, Shaw LM. (2014a). History of cigarette smoking in cognitively-normal elders is associated with elevated cerebrospinal fluid biomarkers of oxidative stress. Drug Alcohol Depend 142:262-268.

Eimer WA, Kumar V, Navalpur Shanmugam NK, Mitchell T, Washicosky KJ, Gyorgy B, et al. (2018). Alzheimer's disease-associated Betaamyloid is rapidly seeded by Herpesviridae to protect against brain infection. Neuron 100(6):1527-1532.

Erickson MA, Banks WA. (2013). Blood-brain barrier dysfunction as a cause and consequence of Alzheimer's disease. J Cerebral Blood Flow Metab 33:1500-1513.

Fafara A, Ciesielska N, Damiza A, Chatys Z, Bentryn D, Gajos A, et al. (2014). Comorbidities disorders and Alzheimer's disease. J Health Sci 4(6):57-70.

Guillaumet-Adkins A, Yanez Y, Preis-Diaz MD, Calabria I, PalanciaBallester C, Sandoval J. (2017). Epigenetics and oxidative stress in aging. Ox Med Cell Longevity Article No. ID9175806. doi: $10.1155 / 2017 / 9175806$

Honjo K, van Reekum R, Verhoeff NP. (2009). Alzheimer's disease and infection: do infectious agents contribute to proression of Alzheimer's disease? Alzheimers Dement 5(4):348-360.

Huang TT, Leu D, Zou Y. (2015). Oxidative stress and redox regulation on hippocampal-dependent cognitive functions. Arch Biochem Biophys 576:2-7.

Huang WJ, Zhang X, Chen WW. (2016). Role of oxidative stress in Alzheimer's disease (review). Biomed Rep 4:519-22.

Jiang T, Yu JT, Tian Y, Tan L. (2013). Epidemiology and etiology of Alzheimer's disease: From genetic to non-genetic factors. Curr Alzheimer Res 9:852-867.

Justice NJ. (2018). The relationship between stress and Alzheimer's disease. Neurobiol Stress 8:127-133.

Kamat PK, Kalani A, Rai S, Swarnkar S, Tota S, Nath C, Tyagi N. (2016). Mechanism of oxidative stress and synapse dysfunction in the pathogenesis of Alzheimer's disease: Understanding the therapeutics strategies. Mol Neurobiol 53(1):648-661.

Karim S, Mizra, Kamal MA, Abuzenadah AM, Azher EI, Al-Qahtani MH, Sohrab SS. An association of virus infection with type 2 diabetes and Alzheimer's disease. (2014). CNS Neurol Discord Drug Targets 13(3):429-439.

Karki R, Kodamullil AT, Hoffmann-Apitius M. (2017). Comorbidity analysis between Alzheimer's disease and type 2 diabetes mellitus (T2DM) based on shalred pathways and the role of T2DM drugs. J Alzheimer's Dis 60:721-731.

Kilian J, Kitazawa M. 2018. The emerging risk of exposure to air pollution on cognitive decline and Alzheimer's disease - Evidence from epidemiological and animal studies. Biomed J 41(3):141-162.

Kuang D, Zhang W, Deng Q, Zhang X, Huang K, Guan L, et al. (2013). Dose-response relationships of polycyclic aromatic hydrocarbons exposure and oxidative damage to DNA and lipid in coke oven workers. Environ Sci Technol 47(13):7446-7456.

Lee HJ, Park MK, Seo YR. (2018). Pathogenic mechanisms of heavy metal induced-Alzheimer's disease. Toxicol Environ Sci 10(1):1-10.

Lehrer S, Rheinstein PH, Rosenzweig KE. (2017). Association of radon background and total background ionizing radiation with Alzheimer's disease deaths in U.S. states. J Alzheimers Dis 59(2):737-741.

Liu Z, Li T, Wei N, Zhao Z, Liang H, Ji X, et al. (2015). The ambiguous relationship of oxidative stress, tau hyperphosphorylation, and autophagy dysfunction in Alzheimer's disease. Oxidative Med Cellular Longevity Article ID 352723. http://dx.doi.org/10.1155/2015/352723. Accessed February 1, 2019.

Lockhead JJ, McCaffrey G, Quigley CE, Finch J, DeMarco KM, Nametz N, Davis TP. (2010). Oxidative stress increases blood-brain barrier permeability and induces alterations in occludin during hypoxiareoxygenation. J Cerebral Blood Flow Metab 30:1625-1636.

Luchsinger JA, Tang MX, Shea S, Mayeux R. (2002). Caloric intake and the risk of Alzheimer disease. (2002). Ach Neur 59(8):1258-1263.

Machado, A, Herrera AJ, de Pablos RM, Espisona-Oliva AM, Sarmeinto M, Ayala A, et al. (2018). Chronic stress as risk factor for Alzheimer's disease. Rev Neurosci 25(6):785-804,
Misiak B, Leszek J, Kiejna A. (2012). Metabolic syndrome, mild cognitive impairment and Alzheimer's disease--the emerging role of systemic low-grade inflammation and adiposity. Brain Res Bull 89(3-4):144149.

Mons U, Schottker B, Muller H, Kliegel M, Brenner H. (2013). History of lifetime smoking, smoking cessation and cognitive function in the elderly population. Eur J Epidemiol 10:823-831.

Moulton PV, Yang W. (2012). Air pollution, oxidative stress, and Alzheimer's disease. J Environ Pub Health, Article ID 472751, deoi:10.1155/2012/47251. Accessed January 5, 2019.

Naderali EK, Ratcliffe SH, Dale MC. (2009). Obesity and Alzheimer's disease: A link between body weight and cognitive function in old age. Am J Alzheimer's Dis \& Other Dementias 24(6):445-449.

Najjar S, Pearlman DM, Devinsy O, Najjar A, Zagzag D. (2013). Neurovascular unit dysfunction with blood-brain barrier hyperpermeability contributes to major depressive disorder: a review of clinical and experimental evidence. J Neuroinflammation 10:142.

http://www.jneuroinflammation.com/content/10/1/142. Accessed March 1, 2019.

Nation DA, Sweeney MD, Montagne AM Abhay P, Sagare AP, D'Orazio LM, et al. (2019). Blood-brain barrier breakdown is an early biomarker of human cognitive dysfunction. Nature Magazine. https://www.nature.com/articles/s41591-018-0297-y. Accessed January 31, 2019.

National Institute of Aging. United States National Institute of Health. (2015).

https://www.nia.nih.gov/health/alzheimers-disease-genetics-fact-sheet. Accessed April 6, 2019.

Nielsen F, Mikkelsen BB, Niesen JB, Andersen HR, Grandjean P. (1997). Plasma malondialdehyde as biomarker for oxidative stress: reference interval and efforts of life-style factors. Clin Chem 43(7):1209-1214.

Ott A, Slooter AJ, Hofman A, van Harskamp E, Witteman JC, Van Broeckhoven C, et al. (1998). Smoking and risk of dementia and Alzheimer's disease in a population-based cohort study: the Rotterdam Study. Lancet 351(9119):1840-1843

Poblador-Plou B, Calderon-Larranage A, Marta-Moreno J, HanccoSaavedra J, Sicras-Mainar A, Solijak M, Prados-Torres A. (2014). Comorbidity of dementia: a cross-sectional study of primary care older patients. BMC 14:84 www.biomedcentral.com/1471-244X/14/84. Accessed January 11, 2019.

Profenno LA, Porsteinsson AP, Faraone SV. Meta-analysis of Alzheimer's disease risk with obesity, diabetes and related disorders. (2010). Biol Psych 67(6):505-512.

Perry G, Cash AD, Smith MA. (2002). Alzheimer's disease and oxidative stress. J Biomed Biotechnol 2(3):12-123.

Ramos-Cejudo, J, Wisniewski T, Marmar C, Zetterberg H, Biennow K, de Leon MJ, Fossati S. (2018). Traumatic brain injury and Alzheimer's disease: The cerebrovascular link. EBioMedicine: 21-30. dou: 10.1016/j.ebiom.2018.01.021. Accessed January 14, 2019.

Redhead B, Haure-Mirande, Funk CC, Richards MA, Shannon P, Haroutunian V, et al. (2018). Multiscale analysis of independent Alzheimer's cohorts find disruption of molecular, genetic, and clinical networks by human Herpesvisus. Neuron 99:64-82

Sabbagh MN, Malek-Ahmadi R, Belden CM, Connor DJ, Pearson C, Jacobson R, et al. (2010). Alzheimers Dis 22(3):1015-1021.

Sochocka M, Zwolinska K, Leszek J. The infectious etiology of Alzheimer's disease. (2017). Curr Neuropharmacol 15:9967-1009.

Tang FR. (2018). Radiation and Alzheimer's disease. J Alzheimer's Dis \& Parkinsonism 8(1). doi: 10.4172/2161-0460.1000418. Accessed January 8, 2019.

Tonnies E, Trushina E. (2017). Oxidative stress, synaptic dysfunction, and Alzheimer's disease. J Alzheimer's Dis 57:1105-1121.

Trempe CL, Lewis TJ. (2018). Its never too early of too late-to end the epidemic of Alzheimer's by preventing or reversing causation from pre-birth to death. Front Aging Neurosci. doi 10.3389/fragi.2018.00205. Accessed March 6, 2019.

Turner RC, Lucke-Wald BP, Robson MJ, Lee ML, Bailes JE. (2016) Alzheimer's disease and chronic traumatic encephalopathy. Baing Inj 30(11):1279-1292

Willcox DC, Scapagnini G, Willcox BJ. (2014). Healthy aging diets other than the Mediterranean: A focus on the Okinawan diet. Mech Ageing Dev 136-137:148-162.

Yan D, Zhang Y, Liu L, Yan H. (2016). Pesticide exposure and risk of Alzheimer's disease: a systematic review and meta analysis. Sci Reports 6: 32222. doi: 10.1038/srep32222. Accessed January 5, 2019.

Yanjun L, Yongming L, Xiaotao L, Zhang S, Zhao J, Zhu X. (2017). Head injury as a risk factor for dementia and Alzheimer's disease: A systematic review and meta-analysis of 32 observational studies. 
PLOS ONE 12(1):e0169650. doi: 10.1371/journal.pone.0169650. Accessed January 13, 2019.

Yuan SH, Wang SG. (2018). Alzheimer's dementia due to suspected CTE from subconcussive head impact. Case Reports Neurol Med, Article ID 7890269. https//doi.org/10.1155/2018/7890269. Accessed January 3, 2019.

Zeliger HI. (2014). Co-morbidities of environmental diseases: A common cause. Interdisip Toxicol 7(3):101-106

Zeliger HI. (2017). Oxidative stress index predicts disease onset. J Med Res Prac 6(3):86-92.

Zeliger HI. (2016). Predicting disease onset in clinically healthy people. Interdiscip Toxicol 9(2):15-21.

Zeliger HI, Lipinski B. (2015). Physiochemical basis of human degenerative disease. Interdiscip Toxicol 8(1):39-54.

Zhang F, Jiang L. (2015). Neuroinflammtion in Alzheimre's disease. Neuropsychiatric Disease Treatment 11:243-256. 